\title{
Radiographic Lung Disease and Response of Persistent Pulmonary Hypertension to Mean Airway Pressure and Alkalosis
}

\begin{abstract}
Karl S. Deluga, ${ }^{1}{ }^{1}$ and Alan E. Schlesinger, ${ }^{2}{ }^{2}$
Summary. Persistent pulmonary hypertension of the newborn (PPHN) is associated with multiple cardiopulmonary diseases. Therapy often includes hyperventilation/alkalosis despite little evidence as to its efficacy in diverse conditions. To determine (1) if part of the improvement of arterial oxygen tension $\left(\mathrm{P}_{\mathrm{a}_{\mathrm{O}}}\right)$ attributed to alkalosis is actually related to increased mean airway pressure $\left(\mathrm{P}_{\mathrm{aw}}\right)$ and (2) if the presence of radiographic pulmonary disease predicts the response to alkalosis or mean airway pressure, we reviewed records of 19 newborns with well-documented $\mathrm{PPHN}$. Arterial blood gases and corresponding ventilator settings were recorded during the first day of life. To adjust for lower $\mathrm{F}_{\mathrm{i}_{2}}$, corrected $\mathrm{P}_{\mathrm{aO}_{2}}\left(\mathrm{cP}_{\mathrm{aO}_{2}}\right)$ was calculated when the $\mathrm{F}_{\mathrm{i}_{2}}<1.0$, such that $\mathrm{CP}_{\mathrm{aO}_{2}}=$ calculated arterial/alveolar oxygen ratio $\times\left(713-\mathrm{P}_{\mathrm{aCO}_{2}} / 0.8\right)$. Regression equations were obtained and mean slopes of these were compared for $\mathrm{P}_{\mathrm{aw}} \mathrm{vs}_{2} \mathrm{cP}_{\mathrm{a}_{\mathrm{O}}}$, and $\mathrm{pH}$ vs. $\mathrm{CP}_{\mathrm{aO}_{2}}$ by one group t-tests (with assumed population slope of zero). There was nô correlation between $\mathrm{P}_{\mathrm{aw}}$ and $\mathrm{CP}_{\mathrm{a}_{\mathrm{O}}}$ (mean slope $\pm \mathrm{SD}=-8.4 \pm 30.8, P=0.25$ ), but there was a moderate correlation between $\mathrm{pH}^{3}$ and $\mathrm{cP}_{\mathrm{a}_{2},}$ (mean slope $=333.1 \pm 480.5, P=0.007$ ). Patients were then classified by chest radiographs as having severe or minimal/no lung disease. Relationships of $\mathrm{P}_{\mathrm{aw}}$ and $\mathrm{pH}$ to $\mathrm{CP}_{\mathrm{aO}_{2}}$ were then re-examined. No correlation was present between $\mathrm{P}_{\mathrm{aw}}$ and $\mathrm{cP}_{\mathrm{a}_{2}}$ in 11 patients with PPHN and severe radiographic disease (mean slope $=-7.4 \pm 26.9$, $P=0.38$ ) or in eight patients with $\mathrm{PPHN}$ and minimal/no lung disease (mean slope $=-9.8 \pm 37.5, P=0.48$ ). There was no correlation between $\mathrm{pH}$ and $\mathrm{CP}_{\mathrm{a}_{\mathrm{O}}}$ in patients with severe radiographic lung disease and $\mathrm{PPHN}$ (mean slope $=92.1 \pm 399.5, P \stackrel{\mathrm{aO}_{2}}{=} 0.46$ ), but patients with $\mathrm{PPHN}$ and minimal/no lung disease showed a strong correlation (mean slope $=664.5 \pm 385.8, P=0.002)$. We conclude that $\mathrm{P}_{\text {aw }}\left(\leqslant 18 \mathrm{~cm} \mathrm{H}_{2} \mathrm{O}\right)$ with conventional mechanical ventilation has no apparent effect on oxygenation in patients with $\mathrm{PPHN}$ regardless of lung disease; however, severe radiographic lung disease may be a predominant variable predicting a poor response to alkalosis. We speculate that different diseases cause pulmonary hypertension by different mechanisms. Pediatr Pulmonol. 1994; 17:239-245.

(c) 1994 Wiley-Liss, Inc.
\end{abstract}

Key words: Pulmonary hypertension, airway pressure, newborn infant, persistent fetal circulation.

\section{INTRODUCTION}

Despite advances in treatment, persistent pulmonary hypertension of the newborn (PPHN) remains a poorly understood entity and a vexing management problem. Initially Gersony et al.' described two patients with clear lung fields and elevated pulmonary artery pressures; however, since that time multiple conditions have been described as causing or being associated with PPHN, including cardiac dysfunction, aspiration syndromes, shock, sepsis, and respiratory distress syndrome. ${ }^{2-6}$

Concomitant with the delineation of the associated conditions, Peckham et al. ${ }^{7}$ and Drummond et al. ${ }^{8}$ documented the use of hyperventilation for lowering pulmonary artery pressure. In demonstrating the association between increased arterial $\mathrm{P}_{\mathrm{a}_{\mathrm{O}},}$ and decreased $\mathrm{P}_{\mathrm{a}_{\mathrm{co}}}$ or alkalosis, these studies did not consider other variables, such as changes in mean airway pressure possibly occurring during hyperventilation or different underlying lung disease. Despite the uncontrolled nature of these studies and the small number of patients, hyperventilation became a common method of treating PPHN. Only recently has the need for hyperventilation been questioned, ${ }^{6}$ and this strategy remains controversial.

From the Department of Pediatrics' and Radiology, ${ }^{2}$ University of Michigan Medical Center, Ann Arbor, Michigan.

Received May 16, 1993; (revision) accepted for publication November 27,1993

Address correspondence and reprint requests to Dr. K. S. Deluga, Northwest Ohio Neonatal Associates, 2142 N. Cove Blvd., Toledo, $\mathrm{OH} 43606$. 
In view of the diversity of underlying pulmonary disorders, it seems unwise to consider PPHN as a single entity. The wide variety of conditions associated with PPHN suggests that the mechanisms causing elevated pulmonary vascular resistance may be different and thus the response to treatment may differ. It is plausible that the treatment of PPHN should be based on the underlying diagnosis rather than the presence of PPHN.

We reviewed a population of babies diagnosed as having PPHN in an attempt to answer two questions: (1) Is part of the increased $\mathrm{P}_{\mathrm{a}_{\mathrm{O}_{2}}}$ that is attributed to increasing $\mathrm{pH}$ actually due to increases in mean airway pressure occuring during the management of PPHN? (2) Does the presence or absence of radiographic lung disease affect the relationship of $\mathrm{pH}$ (or mean airway pressure) to $\mathrm{P}_{\mathrm{a}_{\mathrm{O}_{2}}}$ ?

\section{MATERIALS AND METHODS}

Records of babies admitted to the University of Michigan Holden Neonatal Intensive Care Unit from 1/1/88 until 7/1/92 with the discharge diagnosis of PPHN were considered. In order to eliminate inconsistencies in the diagnosis of PPHN and to avoid the uncertain effects of pulmonary injury induced by oxygen or barotrauma, ${ }^{9}$ only infants who were inborn or transferred from level one or two nurseries in the first day of life were included. In addition, babies who had major congenital anomalies, who did not have an indwelling post-ductal arterial catheter or who were not mechanically ventilated in the first 24 hours of life were excluded from further review.

The diagnosis of PPHN was confirmed based on the following criteria:

1. Gestational age $\geqslant 34$ weeks.

2. Hypoxemia $\left(\mathrm{P}_{\mathrm{a}_{\mathrm{O}}} \leqslant 70\right)$ on at least three arterial blood gases $(\mathrm{ABG})$ during adequate mechanical ventilation with $\mathrm{F}_{\mathrm{i}_{\mathrm{O}_{2}}} \geqslant 0.90$.

3. Normal intracardiac anatomy (VSD, ASD, or PDA are acceptable) with:

a. pre/post-ductal $P_{a_{\mathrm{O}_{2}}}$ difference $\geqslant 20$ torr by $A B G$ or transcutaneous $P_{a_{O_{2}}}$ monitor, or $\geqslant 10 \%$ difference in oximetry; or

b. echocardiographic doppler documentation of right to left or bidirectional atrial or ductal shunt, or decreased right ventricular function with tricuspid regurgitation; or

c. estimated measurement of right ventricular systolic pressure by regurgitant tricuspid jet velocity to be $\geqslant 90 \%$ of systemic.

Infants were ventilated with either Sechrist IV-100B or Bird V.I.P. ventilators. The respiratory records of those babies meeting the diagnostic criteria for PPHN were then examined. Blood gas values and ventilator settings of the first 24 hours of life were recorded. If an infant required extracorporeal life support (ECMO) or high frequency oscillatory ventilation (HFOV) before 24 hours of age, no blood gas values after commencing these rescue therapies were recorded or analyzed.

In order to standardize the $\mathrm{P}_{\mathrm{a}_{\mathrm{O}_{2}}}$ in the event an infant was receiving $\mathrm{F}_{\mathrm{i}_{2}}<1.0$, the $\mathrm{cP}_{\mathrm{a}_{\mathrm{O}_{2}}}$ was calculated. This value was used to estimate what the $P_{\mathrm{a}_{\mathrm{O}} \text {, }}$ would be if the patient were receiving $\mathrm{F}_{\mathrm{i}_{2}} 1.0$, by assuming the arterial/ alveolar oxygen tension (a/A) ratio to be similar in either instance. The $\mathrm{cP}_{\mathrm{a}_{\mathrm{O}}}$, was determined by first calculating the a/A ratio for each arterial blood gas:

$$
\mathrm{P}_{\mathrm{A}_{\mathrm{O}_{2}}}=\left(713 \times \mathrm{F}_{\mathrm{i}_{2}}\right)-\mathrm{P}_{\mathrm{a}_{\mathrm{CO}_{2}}} / 0.8
$$

where $\mathrm{P}_{\mathrm{A}}$, is alveolar oxygen. The a/A ratio was then multiplied by what the alveolar oxygen level would be if the $\mathrm{F}_{\mathrm{i}_{2}}$ were 1.0 , to yield $\mathrm{cP}_{\mathrm{a}_{\mathrm{O}_{2}}}$ :

$$
\mathrm{cP}_{\mathrm{a}_{\mathrm{O}_{2}}}=\mathrm{a} / \mathrm{A} \text { ratio } \times\left(713-\mathrm{P}_{\mathrm{a}_{\mathrm{CO}_{2}}} / 0.8\right) .
$$

The relationships between mean airway pressure and $\mathrm{cP}_{\mathrm{a}_{(2)}}$, and between $\mathrm{pH}$ and $\mathrm{cP}_{\mathrm{a}_{0}}$ were examined in babies meeting diagnostic criteria for PPHN. Regression equations and correlation coefficients ( $r$ values) were determined for $\mathrm{pH}$ vs. $\mathrm{CP}_{\mathrm{a}_{\mathrm{O}_{2}}}$, and $\mathrm{P}_{\mathrm{aw}}$ vs. $\mathrm{cP}_{\mathrm{a}_{\mathrm{a}_{2}}}$ in each patiènt. For each of the two different correlations, the regression equations of the individual patients were used to determine the mean slope $( \pm S D)$ for all patients. The mean slope was compared by one group t-test to an assumed population mean slope of zero (no correlation). Correlations after radiographic stratification (see below) were compared in the same fashion. A $P$-value $\leqslant 0.008$, after Bonferroni correction for multiple comparisons, was accepted as indicating a significant difference. The mean of individual $r$ values of each group is reported, but was not used in the statistical analysis.

The chest radiographs of all PPHN infants were initially reviewed separately by a neonatologist (KSD) and a pediatric radiologist (AES). The patients were separated based on the chest radiographic findings from the first day of life into two groups: those with minimal or no apparent lung disease and those with severe lung abnormalities. Lung conditions diagnosed radiographically included respiratory distress syndrome (RDS), meconium aspiration syndrome (MAS), pneumonia, retained lung fluid, and nonspecific abnormalities (e.g., haziness, mild granularity). Differences between the two reviewers were resolved by consensus after joint review of radiographs. Both viewers were unaware of the clinical course of the patients being re-reviewed until after consensus was reached.

Similar correlations of $\mathrm{P}_{\mathrm{aw}}$ vs. $\mathrm{cP}_{\mathrm{a}_{0}}$ and pH'vs. $\mathrm{cP}_{\mathrm{a}_{02}}$ were assessed for patients based on their radiographic group assignments, PPHN with minimal/no lung disease, or PPHN with severe lung disease. Mean slopes ( \pm SD) 
TABLE 1-PPHN Patients-Descriptive Data ${ }^{a}$

\begin{tabular}{|c|c|c|c|}
\hline & $\begin{array}{l}\text { All patients } \\
(\mathrm{n}=19)\end{array}$ & $\begin{array}{l}\text { Minimal/no lung } \\
\text { disease }(\mathbf{n}=\mathbf{8})\end{array}$ & $\begin{array}{c}\text { Severe lung } \\
\text { disease }(n=11)\end{array}$ \\
\hline Weight (kg \pm SD) & $3.40 \pm 0.80$ & $3.59 \pm 0.93$ & $3.27 \pm 0.64$ \\
\hline Gest. age (wks) & $38.6 \pm 2.1$ & $38.2 \pm 1.2$ & $3.87 \pm 2.6$ \\
\hline $\operatorname{Sex}(M / F)$ & $10 / 9$ & $5 / 3$ & $5 / 6$ \\
\hline $\mathrm{P}_{\mathrm{a}_{\sigma_{0}}}$ (Torr $\left.\pm \mathrm{SD}\right)^{\mathrm{b}}$ & & $83 \pm 87$ & $88 \pm 55$ \\
\hline $\mathrm{P}_{\mathrm{aw}}^{\mathrm{aO}_{\mathrm{O}}}\left(\mathrm{cm} \mathrm{H} \mathrm{H}_{2} \mathrm{O} \pm \mathrm{SD}\right)^{\mathrm{b}}$ & & $12.5 \pm 2.5$ & $11.3 \pm 1.8$ \\
\hline $\mathrm{FiO}_{2} *( \pm \mathrm{SD})$ & & $0.96 \pm 0.15$ & $0.92 \pm 0.17$ \\
\hline $\mathrm{pH}^{\mathrm{c}^{\mathrm{s}}}$ & & 7.49 & 7.37 \\
\hline \multicolumn{4}{|l|}{ Other diagnoses } \\
\hline MAS & 3 & & 3 \\
\hline RDS & 2 & & 2 \\
\hline Asphyxia & 4 & 4 & \\
\hline Presumed sepsis & 2 & 2 & \\
\hline Pneumonia (?) & 6 & 2 & 4 \\
\hline Shock lung (?) & 2 & & 2 \\
\hline
\end{tabular}

MAS, meconium aspiration syndrome; RDS, respiratory distress syndrome.

${ }^{a}$ Descriptive information on 19 patients fulfilling criteria for the diagnosis of PPHN. Diagnoses in question were thought to be the most likely clinical diagnoses by the attending physician. No patients had positive blood or CSF cultures.

bean values during the first 6 hours of life.

${ }^{c}$ Median values during the first 6 hours of life.

for each group were again determined and tested against an assumed population value of zero, as above.

\section{RESULTS}

Between 1/1/88 and 7/1/92, 177 patients were admitted with a discharge diagnosis of PPHN. Of these, 33 patients were identified who had no significant congenital anomalies, and were either inborn or transferred from level one or two nurseries in the first 24 hours of life. Seven of these were eliminated because they had no postductal arterial line $(n=5)$ or had not undergone mechanical ventilation in the first day of life $(n=2)$. The remaining 26 patients were reviewed in detail.

Of the remaining 26 patients, 7 did not meet the diagnostic criteria for PPHN, 4 had echocardiograms which did not meet criteria for PPHN, and 3 patients had fewer than three $\mathrm{P}_{\mathrm{a}_{3}} \leqslant 70$ torr during mechanical ventilation with $F_{i_{\mathrm{O}_{2}}} \geqslant 0.90$. Nineteen patients met the criteria for the diagnosis of PPHN. Descriptive information for the 19 patients with PPHN is shown in Table 1. During the time period encompassed by these patients, hyperventilation with adjunctive alkali therapy (sodium bicarbonate) was generally the treatment for PPHN in this unit. Supportive therapy usually also included antibiotic coverage, intravascular volume expansion, pressors, sedation, and pancuronium. Only one infant received exogenous surfactant.

Sixty-six of the $233(28.3 \%) \mathrm{P}_{\mathrm{a}_{\mathrm{O}}}$ values were obtained when the $\mathrm{F}_{\mathrm{i}_{\mathrm{O}_{2}}}<1.0\left(\mathrm{~F}_{\mathrm{i}_{\mathrm{O}_{2}}}\right.$ range, $\left.0.60-1.0\right)$, and $\mathrm{P}_{\mathrm{i}_{\mathrm{CO}_{2}}}$ was calculated to correct for the lower $\mathrm{F}_{\mathrm{i}_{2}}$ in these instances. In general, the correction was very modest, because the

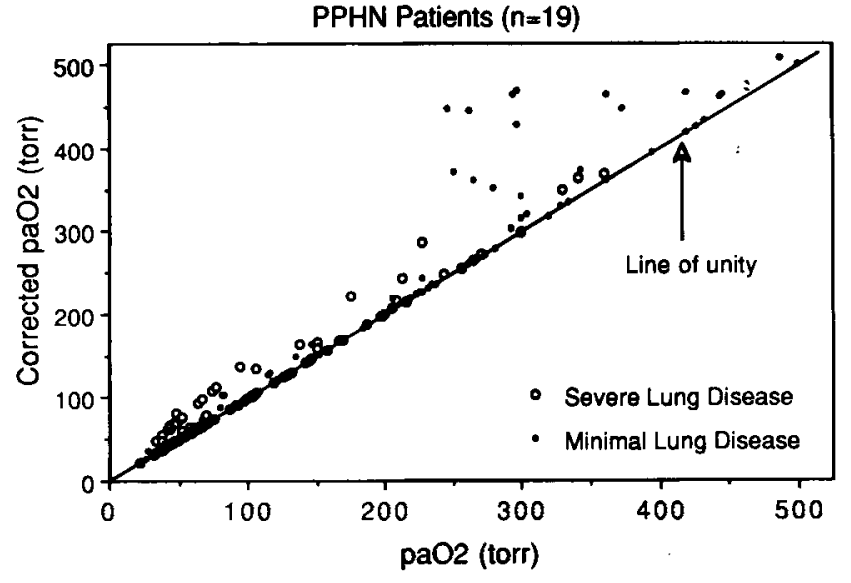

Fig. 1. Comparison of $\mathbf{P}_{\mathrm{ao},}$ to corrected $\mathrm{CP}_{\mathrm{ao}}$. Magnityde of correction is vertical distance from any given point to line of unity. Large corrections result when $\mathrm{P}_{\mathrm{aO}_{2}}$ is already high or when $\mathrm{F}_{\mathrm{iO}_{2}}$ is
well below 1.0.

$\mathrm{F}_{\mathrm{i}_{\mathrm{O}_{2}}}$ was usually near 1.0 and/or the a/A ratio was quite low. Large corrections occurred only in the few instances when the $\mathrm{P}_{\mathrm{a}_{\mathrm{O}_{2}}}$ was already high and the $\mathrm{F}_{\mathrm{i}_{2}}$ relatively low (Fig. 1).

In the 19 patients with PPHN, no correlation was found between mean airway pressure and $\mathrm{cP}_{\mathrm{a}_{\mathrm{O}_{2}}}$ (mean slope $\pm \mathrm{SD}=-8.42 \pm 3082 ; \quad P=0.25 ;$ mean $\mathrm{r}=$ $0.01)$. A modest, but significant, correlation was found between $\mathrm{pH}$ and $\mathrm{cP}_{\mathrm{a}, 2}$ (mean slope $=333.1 \pm 480.5$, $P=0.007$, mean $\mathrm{r}=0.38$ ) in PPHN patients (Fig. 2).

After PPHN patients were categorized by the severity of radiographic lung disease the severe and minimal lung disease groups did not differ statistically during the first 6 

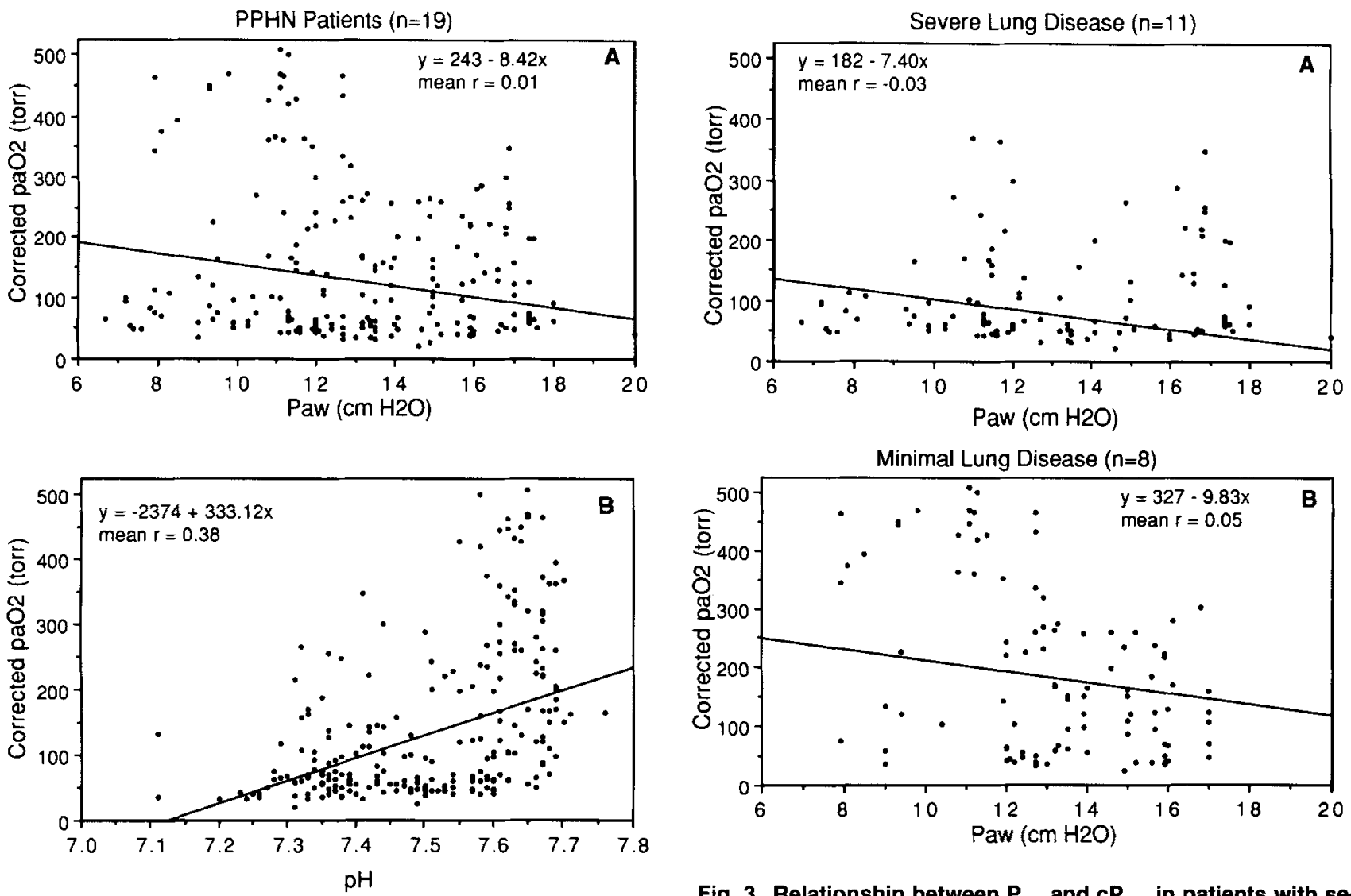

Fig. 2. Relationships between $P_{\text {aw }}$ and $c P_{a_{0}}(A)$, and $p H$ and $\mathrm{CP}_{\mathrm{aO}_{2}}(\mathrm{~B})$, in all patients fulfilling diagnostic criteria for PPHN. Regression equations, lines, and $r$ values are the mean values obtained from individual correlations. There is a significant correlation based on mean slope between $\mathrm{pH}$ and $\mathrm{CP}_{\mathrm{aO}_{2}}(P=0.007)$ in PPHN patients as a group.

hours of life with respect to mean $( \pm \mathrm{SD}) \mathrm{P}_{\mathrm{a}_{02}}(88 \pm 55$ vs. $83 \pm 87), \mathrm{P}_{\text {aw }}(11.35 \pm 1.84$ vs. $12.52 \pm 2.53)$, or $F_{i_{O_{2}}}(0.92 \pm 0.17$ vs. $0.96 \pm 0.15)$, respectively. However, the median $\mathrm{pH}$ was slightly lower when in the presence of severe lung disease was (7.37 vs. 7.49).

After radiographic stratification, no correlation was found between $\mathrm{P}_{\mathrm{aw}}$ and $\mathrm{cP}_{\mathrm{a}_{0}}$ in patients with severe lung disease (mean slope $=-7.40 \pm 26.9 ; P=0.38$; mean, $\mathrm{r}=-0.03$ ) or patients with minimal lung disease (mean slope $=-9.83 \pm 37.5 ; P=0.48$; mean $r=0.05$ ) (Fig. 3 ). Conversely, in patients with severe lung disease and PPHN, there was no correlation between $\mathrm{pH}$ and $\mathrm{CP}_{\mathrm{a}_{2}}$ (mean slope $=92.10 \pm 399.5 ; \quad P=0.46 ; \quad$ mean $\mathrm{r}=0.20$ ), but if only minimal lung disease was present the correlation was strong (mean slope $=664.5 \pm$ $385.8 ; P=0.002$, mean $\mathrm{r}=0.64$ ) (Fig. 4).

Of the 11 patients with PPHN and severe lung disease 7 eventually required ECMO, compared to only 2 of 8 in the PPHN/minimal lung disease group. Two patients with severe lung disease were treated with HFOV at 14.5 and

Fig. 3. Relationship between $P_{a w}$ and $c P_{a o}$ in patients with severe lung disease (A) and minimal lung disease $(B)$ by chest radiography. Regression equations, lines, and $r$ values are means obtained from individual correlations.

19 hours of life, and both were subsequently treated with ECMO within 3.5 hours. Blood gas data during ECMO or HFOV were not included in data analysis.

\section{DISCUSSION}

Drummond et al. ${ }^{8}$ convincingly showed a correlation between increased arterial $\mathrm{pH}$ induced by vigorous ventilation and increased $\mathrm{P}_{\mathrm{a}_{2}}$ in babies with pulmonary hypertension. Increased minute ventilation may be accomplished with increased, decreased, or unchanged $\mathrm{P}_{\mathrm{aw}_{i}}$. However, it seems likely that substantially increased $P_{a w}$ will occur as respiratory support is increased while the diagnosis is confirmed and during early management of patients with PPHN. Then, depending on the approach of the clinician, further increases in $\mathrm{P}_{\mathrm{aw}}$ might also occur during the hyperventilation process. Thus, some or all of the increase in $\mathrm{P}_{\mathrm{a}_{2}}$ attributed to alkalosis might actually be due to improved lung inflation and aiveolar recruitment because of increased $P_{a w}$. This concurrent change was not considered for its possible effect on $\mathrm{P}_{a_{\mathrm{O}_{2}}}$ by Drummond. We attempted to examine the relationship of $P_{a w}$ to $P_{a_{0},}$ in patients with PPHN. 

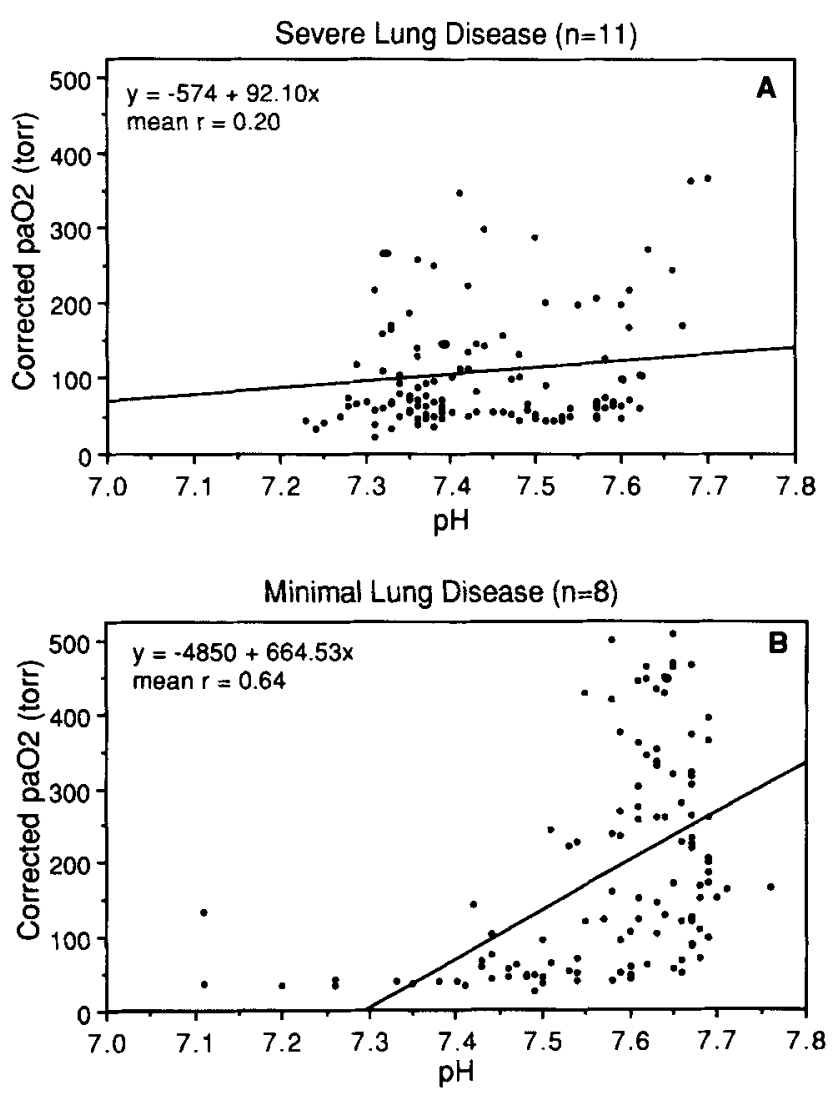

Fig. 4. Relationship between $\mathrm{pH}$ and $\mathrm{cP}_{\mathrm{a}_{0}}$ in patients with severe lung disease (A) and minimal lung disease $(B)$ by chest radiography. Regression equations, lines, and $r$ values are means obtained from individual correlations. There is a significant correlation in patients with minimal lung disease $(P=0.002)$.

Although previous studies have documented the effects of $\mathrm{P}_{\mathrm{aw}}$ on $\mathrm{P}_{\mathrm{a}_{\mathrm{O}_{2}}}$ in newborns with RDS, ${ }^{10,11}$ our data do not support the contention that increases of mean airway pressure during the management of patients with PPHN have a significant effect on $P_{\mathrm{a}_{0}}$. The mean slope of regression lines did not differ significantly from zero. In addition, correlation coefficients from only 2 of 19 patients were greater than 0.50 (range, $-0.78-0.56$ ), and many ( 8 of 19 ) had negative $r$ values.

Several explanations may account for the poor correlation between $P_{a w}$ and $P_{a_{O} 2}$. Mean airway pressure can be changed in multiple ways, many of which may be ineffective at increasing $\mathrm{P}_{\mathrm{a}_{\mathrm{O}_{2}}}$ depending on underlying lung disease, cardiac function, and other patient-specific factors. Thus, the benefit of one method of increasing $P_{a w}$ might be obscured by other maneuvers which, although they increase $P_{a w}$, do not improve oxygenation. In addition, the mean airway pressures used in our patients rarely exceeded $18 \mathrm{~cm} \mathrm{H}_{2} \mathrm{O}$, probably reflecting the general clinical management in this neonatal unit. This level may have been insufficient for adequate lung inflation and alveolar recruitment, especially in the face of severe lung disease. Alternatively, the presence of extrapulmonary right to left shunting may be the predominant factor. Mean airway pressure effects on oxygenation would certainly require adequate pulmonary blood flow. If the increased $\mathrm{P}_{\text {aw }}$ did not improve pulmonary flow or ventilation-perfusion $(\dot{V} / \dot{Q})$ matching, oxygenation would not improve. Furthermore, the dynamic, variable nature of shunting during PPHN would make any correlation of $\mathrm{P}_{\mathrm{aw}}$ and $\mathrm{P}_{\mathrm{a}_{\mathrm{O}}}$ even more difficult to demonstrate.

This lack of correlation between $P_{a w}$ and $P_{a_{02}}$ persisted when patients were divided based on the presence or absence of severe lung disease. A more specific categorization of patients by specific pulmonary diagnoses might be informative; however, the number of patients available for review was inadequate to allow this.

Persistent pulmonary hypertension has been associated with a wide spectrum of clinical conditions, yet there is a common tendency to lump PPHN patients together, with PPHN considered the principal clinical problem. The diversity of the associated cardiopulmonary conditions suggests that PPHN is not a single entity, but should be considered in the context of the concomitant conditions. Animal research supports the concept that the mechanisms of pulmonary hypertension are multiple. ${ }^{12-15} \mathrm{We}$ attempted to ascertain the response to alkalosis of babies with PPHN who had either severe or minimal radiographic lung disease. This division was chosen based on the hypothesis that the mechanism of pulmonary hypertension in infants with severe lung disease is often alveolar hypoxia. These babies would, therefore, be expected to be less responsive to alkalosis because of a persistent hypoxic stimulus.

Patients with PPHN as a group showed a modest, statistically significant correlation between $\mathrm{pH}$ and $\mathrm{cP}_{\mathrm{a}_{\mathrm{c}}}$. However, there was considerable individual variability in this relationship. After stratification based on severity of lung disease apparent on chest radiograph, the correlation between $\mathrm{pH}$ and $\mathrm{CP}_{\mathrm{a}_{\mathrm{O}}}$ was much more pronounced in patients having minimal or no apparent lung disease (mean $r=0.64$ ) than in patients with severe lung disease (mean $r=0.20$ ) (Fig. 4). Patients with severe pulmonary parenchymal abnormalities were more resistant to the vasodilatory effects of hyperventilation/alkalosis therapy, suggesting different mechanisms of increased pulmonary vascular resistance.

It might be argued that the lack of response in the infants with severe abnormalities on radiographs is because these babies were more ill, in effect saying, "sicker babies do worse." We do not believe this explanation is representative of the pathophysiology of these two groups of infants. Based on the values of $\mathrm{P}_{\mathrm{a}_{\mathrm{O}_{2}}}, \mathrm{~F}_{\mathrm{i}_{\mathrm{O}_{2}}}$, and $\mathrm{P}_{\mathrm{aw}}$ during the first 6 hours of life, the two groups were comparable. In addition, although it was difficult to achieve a $\mathrm{pH}$ of 7.55 or greater in babies with severe 
radiographic lung abnormalities, only $48 \%(11 / 23)$ of $\mathrm{cP}_{\mathrm{a}_{0 / 2}}$ values were greater than 100 torr when this $\mathrm{pH}$ level was achieved, as opposed to $83 \%(64 / 77)$ of $\mathrm{cP}_{\mathrm{it}_{0}, \text { values }}$ in the minimal lung disease group $(P<0.002$, chi square).

This lack of response to alkalosis in patients with severe lung disease is consistent with the hypothesis that different mechanisms are responsible for pulmonary hypertension in the two groups of patients. There are several obvious hypothetical categories into which patients with PPHN can be placed, in terms of mechanisms of pulmonary hypertension. Patients with mild radiographic parenchymal lung disease would likely be comprised of those with cardiac dysfunction, retained fetal lung fluid, so-called primary PPHN, and possibly sepsis without pneumonia. Although the mechanisms of pulmonary hypertension in these conditions probably differ, none of them would be likely to result in widespread alveolar hypoxia, especially in the face of vigorous ventilation. Without the potent pulmonary vasoconstrictive stimulus of alveolar hypoxia, the pulmonary vasodilatory effects of alkalosis would be more likely to be effective.

Patients with severe parenchymal lung disease would include infants with meconium aspiration syndrome, RDS, shock lung, or pneumonia. Despite vigorous mechanical ventilation, the most severe cases would have continued alveolar hypoxia due to diffuse microatelectasis, alveolar injury and edema, and/or airway obstruction. Atelectasis and alveolar hypoxia in experimental model ${ }^{16}$ increase pulmonary vascular resistance and pulmonary artery pressure. This response is crucial in matching ventilation and perfusion to maintain oxygenation, but when diffuse severe alveolar disease is present, elevated pulmonary vascular resistance, $\dot{V} / \dot{Q}$ mismatch, and right-to-left shunting are common. Alkalosis will attenuate but not abolish pulmonary vasoconstriction if alveolar hypoxia is still present ${ }^{17}$; thus the clinical response to alkalosis would be poor.

In the group of patients with severe lung disease, it can be argued that pulmonary hypertension is the pathologic exaggeration of a "normal" response to the condition of the lungs. Indeed, in the initial description of "PFC Syndrome," Gersony et al. ' stated that the condition "represents a diagnosis of exclusion and is to be distinguished from right-to-left shunting in association with pulmonary disease." Early studies on premature infants with RDS documented that nearly half of these infants exhibited right-to-left ductal shunting, which resulted in a pre/postductal $\mathrm{P}_{\mathrm{a}_{0,}}$ difference of 20 torr or greater. ${ }^{18.19}$ By today's standards, this is generally adequate to make a diagnosis of PPHN. This high proportion of infants having clear evidence of PPHN documents that pulmonary hypertension is very common in the presence of RDS. In addition, these findings suggest that some degree of pul- monary hypertension is the rule rather than the exception with RDS, and it is merely the severity of the pulmonary hypertension in any given case that determines whether a baby is considered to have straightforward RDS or RDS with PPHN. Furthermore, if pulmonary hypertension is indeed a usual accompaniment of severe pulmonary disease, the question arises of whether or not one should attempt to specifically treat this secondary phenomonen. The development of more effective methods of managing severe lung disease in newborns may be the most important factor in treating PPHN; as the lung disease improves, the resolution of the concomitant pulmonary hypertension will follow.

Other forms of severe lung disease may have different or even multiple mechanisms of pulmonary hypertension at work. Pulmonary hypertension in infants with pneumonia and sepsis may be the result of both alveolar hypoxia and vasoactive substances affecting pulmonary vascular tone ${ }^{12.13}$ and cardiac function. Infants with congenital diaphragmatic hernia or pulmonary hypoplasia, not represented in our patients, likely have pulmonary hypertension due pulmonary vascular remodeling.

The marked difference in the response to alkalosis in our two groups of patients is consistent with these clinical categories. This difference in responsiveness may also have implications for therapy. Low likelihood of response to increased $\mathrm{pH}$ during conventional mechanical ventilation. difficulty in hyperventilation, and the possibility that pulmonary hypertension is a "naturally" occurring and reversible part of severe lung injury provide substantive arguments against the use of hyperventilation unless adequate oxygenation cannot be maintained with conventional ventilatory techniques.

In conclusion, no demonstrable effect of mean airway pressure (up to $\mathrm{P}_{\mathrm{aw}}$ of $18 \mathrm{~cm} \mathrm{\textrm {H } _ { 2 }} \mathrm{O}$ ) on oxygenation was noted during conventional mechanical ventilation in patients with PPHN, regardless of the degree of radiographic lung disease present. The response of these patients to alkalosis, however, differed based on underlying radiographic lung disease. Thus, the management of patients with PPHN should take into account the concomitant cardiopulmonary diseases, likely pathophysiologic mechanisms of PPHN, and the likelihood of positive response to any therapy, particularly hyperventilation.

\section{REFERENCES}

1. Gersony WM, Duc GV, Sinclair JC. "PFC" syndrome (Persistence of the fetal circulation). Circulation 1969; 39(Suppl III):87.

2. Riemenschneider TA, Niclson HC, Ruttenberg HD, Jaffe RB. Disturbances of the transitional circulation: Spectrum of pulmonary hypertension and myocardial dysfunction. J Pediatr. 1976; 89:622-625

3. Fox WW, Gewitz MH, Dinwiddie R, Drummond WH, Peckham GJ. Pulmonary hypertension and the perinatal aspiration syndromes. Pediatrics 1977; 59:205-211. 
4. Lock JE, Fuhrman BP, Epstein ML, Rowe RD, Lucas RV. Pulmonary hypertension following neonatal shock. Pediatr Cardiol. 1979/80; 1:109-115.

5. Shankaran S, Farooki ZQ, Desai R. Beta-hemolytic Streptococcal infection appearing as persistent fetal circulation. Am J Dis Child. 1982; 136:725-727.

6. Wung JT, James LS, Kilchersky E, James E. Management of infants with severe respiratory failure and persistence of the fetal circulation, without hyperventilation. Pediatrics 1985; 76:488 494.

7. Peckham GJ, Fox WW. Physiologic factors affecting pulmonary artery pressure in infants with persistent pulmonary hypertension. J Pediatr. 1978; 93:1005-1010.

8. Drummond WH, Gregory GA, Heymann MA, Phibbs RA. The independent effects of hyperventilation, tolazoline, and dopamine on infants with persistent pulmonary hypertension. J Pediatr. 1981; 98:603-611.

9. Sosulski R, Fox WW. Transition phase during hyperventilation therapy for persistent pulmonary hypertension of the neonate. Crit Care Med. 1985; 13:715-719.

10. Herman S, Reynolds EOR. Methods for improving oxygenation in infants mechanically ventilated for severe hyaline membrane disease. Arch Dis Child. 1973; 48:612-617.

11. Boros SJ. Variations in inspiratory:expiratory ratio and airway pressure wave form during mechanical ventilation: The significance of mean airway pressure. J Pediatr. 1979; 94:114-117.

12. Wild LM, Nickerson PA, Morin FC III. Ligating the ductus arte- riosus before birth remodels the pulmonary vasculature of the lamb. Pediatr Res. 1989:25:251-257.

13. Stenmark KR. Fasules J, Hyde DM, Voelkel NF. Henson J, Tucker A, Wilson H, Reeves JT. Severe pulmonary hypertension and arterial adventitial changes in newborn calves at $4.300 \mathrm{~m}$. J Appl Physiol. 1987; 62:821-830.

14. Schreiber MD. Covert RF, Torgerson LJ. Hemodynamic effects of heat-killed group B $\beta$-hemolytic Streptococcus in newborn lambs: Role of leukotriene $D_{4}$. Pediatr Res. 1992; 31:121-126.

15. Hammerman C. Komar K, Abu-Khudair H. Hypoxic vs. septic pulmonary hypertension: Selective role of thromboxane mediation. Am J Dis Child. 1988; 142:319-325.

16. Glasser SA, Domino KB, Lindgren L. Parcella P, Marshall C, Marshall BE. Pulmonary blood pressure and flow during atelectasis in the dog. Anesthesiology 1983; 58:225-231.

17. Lyrene RK, Welch KA, Godoy G, Phillips JB III. Alkalosis attenuates hypoxic pulmonary vasoconstriction in neonatal lambs. Pediatr Res. 1985; 19:1268-1271.

18. Chu J, Clements JA, Cotton EK, Klaus MH, Sweet AY, Tooley WH. Neonatal pulmonary ischemia Part I: Clinical and physiologic studies. Pediatrics 1967; 40:709-782.

19. Murdock AI, Swyer PR. The contribution to venous admixture by shunting through the ductus arteriosus in infants with the respiratory distress syndrome of the newborn. Biol Neonate. 1968; 13: 194-210.

20. Geggel RL, Reid LM. The structural basis of PPHN. Clin Perinatol. 1984; 11:525-549. 